\title{
ЖИРНОКИСЛОТНЫЙ СОСТАВ МАСЛА ПЛОДОВ РАСТОРОПШИ ПЯТНИСТОЙ, КУЛЬТИВИРУЕМОЙ В САМАРСКОЙ ОБЛАСТИ
}

\author{
() В.А. Куркин ", О.В. Сазонова, Д.В. Росихин, Т.К. Рязанова \\ Самарский государственный медицинский университет, ул. Чапаевская, 89, \\ Самара, 443099 (Россия), e-mail: Kurkinvladimir@yandex.ru
}

\begin{abstract}
Плоды расторопши пятнистой [(Silybum marianum (L.) Gaertn.), сем. Астровые - Asteraceae] широко используются в медицинской практике как гепатопротекторное средство благодаря содержащимся в них флаволигнанам. Однако кроме флаволигнанов важной группой биологически активных соединений плодов является жирное масло. Цель исследования - изучение жирнокислотного состава масла плодов расторопши пятнистой, культивируемой в Самарской области с помощью хромато-масс-спектрометрии. В качестве объекта использовали масло, полученное на базе 3АО «Самаралектравы» из плодов расторопши, культивируемой промышленным способом на территории Самарской области. В результате газохроматографического разделения идентифицированы 15 жирных кислот. Основные жирные кислоты масла расторопши были представлены ненасыщенными кислотами - линолевой $\left(\mathrm{C}_{18: 2} ; 34,8 \pm 3,0 \%\right)$ и олеиновой кислотами $\left(\mathrm{C}_{18: 1} ; 25,7 \pm 3,5 \%\right)$, а также насыщенными - стеариновой $\left(\mathrm{C}_{18: 0} ; 11,4 \pm 1,0 \%\right)$, пальмитиновой $\left(\mathrm{C}_{16: 0} ; 9,9 \pm 0,2 \%\right)$, арахиновой $\left(\mathrm{C}_{20: 0} ; 6,9 \pm 0,6 \%\right)$ и бегеновой $\left(\mathrm{C}_{22: 0} ; 3,8 \pm 0,4 \%\right)$. В исследуемых образцах доля ненасыщенных жирных кислот составляла $61 \%$, насыщенных - 39\%. Сопоставление с литературными данными показало, что газохроматографический метод может быть использован для подтверждения подлинности потенциальной фармацевтической субстанции «Масло расторопши пятнистой».

Ключевые слова: расторопша пятнистая, Silybum marianum (L.) Gaertn., плоды, масло расторопши пятнистой, насыщенные и ненасыщенные жирные кислоты.
\end{abstract}

\section{Введение}

Расторопша пятнистая [(Silybum marianum (L.) Gaertn.), сем. Астровые - Asteraceae] содержит уникальную группу биологически активных соединений - флаволигнаны, которые обладают гепатопротекторным, выраженным антиоксидатным и антитоксическим действием. Плоды расторопши пятнистой служат источником получения ценных гепатопротекторных лекарственных средств (легалон, карсил, силимар, силибор и др.) [1-4]. Однако кроме флаволигнанов важной группой биологически активных соединений плодов расторопши пятнистой является жирное масло. Лекарственные препараты на основе масла (натурсил) применяются при лечении язв, ран, пролежней и воспалительных процессов [1]. Масло расторопши оказывают благоприятное действие на липидный обмен (постепенно снижает в крови уровень общего холестерина, триглицеридов и бета-

Куркин Владимир Александрович - заведующий кафедрой фармакогнозии с ботаникой и основами фитотерапии, профессор, доктор фармацевтических наук, тел. (846) 260-33-59, e-mail: Kurkinvladimir@yandex.ru Сазонова Ольга Викторовна - директор НИИ гигиены и экологии человека, доцент, доктор медицинских наук, e-mail: ov_2004@mail.ru

Рязанова Татьяна Константиновна - заведующий лабораторией санитарно-химических методов исследования НИИ гигиены и экологии человека, кандидат фармацевтических наук, тел. (846) 260-33-59, e-mail: ryazantatyana@mail.ru

Росихин Данил Владимирович - аспирант, тел. (846) 260-33-59, e-mail: rocksymbol@mail.ru липопротеинов), при введении внутрь повышает содержание общего белка в крови, снижает процессы трансаминирования и уровня мочевины, стимулирует процессы эритропоэза [5].

Однако данные по жирнокислотному составу масла плодов расторопши ограничены [5-8]. Упоминается о наличии олеиновой, линолевой, стеариновой, пальмитиной и некоторых других кислот. Необходимо также отметить, что количественное содержание флаволигнанов и жирных кислот, содержащихся в плодах расторопши, зависит от особенностей конкретной хеморасы [3].

\footnotetext{
* Автор, с которым следует вести переписку.
} 
В связи с этим цель настоящей работы - изучение состава жирных кислот масла плодов расторопши пятнистой, культивируемой в Самарской области.

\section{Экспериментальная часть}

Объектами исследования служило жирное масло расторопши пятнистой, полученное методом прессования на базе ЗАО «Самаралектравы» из плодов расторопши пятнистой [(Silybum marianum (L.) Gaertn.), сем. Астровые - Asteraceae], культивируемой промышленным способом в Самарской области (2016 г.). Содержание жирного масла в плодах расторопши пятнистой, определенное весовым методом с использованием аппарата Сокслета и хлороформа в качестве экстрагента [1], составило 28,50\%.

Изучение жирнокислотного состава масла плодов проводили методом газожидкостной хроматографии после предварительного перевода жирных кислот в метиловые эфиры по методике ГОСТ 31665-2012, переэтерификацией с метанольным раствором гидроксида калия [9]. Для этого 0,5 г масла помещали в коническую колбу, растворяли в 10 мл $н$-гексана, добавляли 0,5 мл 2 М раствора гидроксида калия в метаноле, закрывали пробкой и интенсивно перемешивали в течение 5 мин. Полученный раствор центрифугировали на лабораторной центрифуге ОПН-3 с частотой вращения 3000 мин $^{-1}$. Для анализа использовали верхний слой.

Состав жирных кислот определяли с помощью газового хроматографа «МАЭСТРО 7820» с массспектрометром модели Agilent 5975 и автоинжектором. Анализ проводили с использованием капиллярной кварцевой колонки НР-5ms 30 м × 0,25 мм $\times 0 ., 25$ мкм (неподвижная фаза: 5\%-дифенил-95\%-диметилсилоксан) фирмы Agilent. Условия хроматографирования: программирование температуры термостата колонок: изотерма $40^{\circ} \mathrm{C}$ в течение 1 мин - нагрев до $210^{\circ} \mathrm{C}$ со скоростью $15^{\circ} \mathrm{C} /$ мин - нагрев до $150{ }^{\circ} \mathrm{C}$ со скоростью $7^{\circ} \mathrm{C} /$ мин - нагрев до $280{ }^{\circ} \mathrm{C}$ со скоростью $5{ }^{\circ} \mathrm{C} /$ мин - изотерма $280{ }^{\circ} \mathrm{C}$ в течение 10 мин; газноситель - гелий, скорость газа-носителя - 1 мл/мин; температура испарителя - $280{ }^{\circ} \mathrm{C}$; температура источника ионов $-150{ }^{\circ} \mathrm{C}$; температура квадруполя $-230{ }^{\circ} \mathrm{C}$; температура переходной камеры $-280{ }^{\circ} \mathrm{C}$; сброс - 1 : 100; объем вводимой жидкой пробы - 1 мкл.

Для идентификации компонентов определяли линейные индексы удерживания, сопоставляли полученные результаты и полные масс-спектры с библиотечными (библиотеки масс-спектров «NIST 2.0») и литературными данными. Рассматривались только компоненты, определяемые по библиотеке с вероятностью более 90\%. Количественный анализ проводили по площадям соответствующих пиков на хроматограмме, построенной по полному ионному току.

\section{Обсуждение результатов}

В результате газохроматографического разделения идентифицированы 15 жирных кислот (табл.). Состав и количественное содержание идентифицированных компонентов жирного масла представлены в таблице. В исследуемом образце представлены ненасыщенные (61\%) и насыщенные жирные кислоты (33\%).

Основной профиль жирного масла на хроматограмме создают ненасыщенные кислоты - линолевая $\left(\mathrm{C}_{18: 2}\right.$; $34,8 \pm 3,0 \%)$ и олеиновая кислоты $\left(\mathrm{C}_{18: 1} ; 25,7 \pm 3,5 \%\right)$, а также насыщенные - стеариновая $\left(\mathrm{C}_{18: 0} 0 ; 11,4 \pm 1,0 \%\right)$, пальмитиновая $\left(\mathrm{C}_{16: 0} ; 9,9 \pm 0,2 \%\right)$, арахиновая $\left(\mathrm{C}_{20: 0} ; 6,9 \pm 0,6 \%\right)$ и бегеновая $\left(\mathrm{C}_{22: 0} ; 3,8 \pm 0,4 \%\right)$ (табл., рис.).

Линолевая кислота является представителем омега-6 жирных кислот и относится к незаменимым. В организме человека она конвертируется в другие $\omega-6$ жирные кислоты, наиболее значимыми из которых являются дигомо- $\gamma$ - линоленовая кислота и арахидоновая кислоты. Обнаруживаемая по литературным данным в масле расторопши линоленовая кислота относится к омега-3 жирным кислотам и является предшественником синтеза в организме длинноцепочечных полиненасыщенных жирных кислот - эйкозапентаеновой и докозагексаеновой. Омега-6 и омега-3 кислоты с участием одних и тех же энзимов превращаются в медиаторы липидной природы - эйкозаноиды, отличающихся по своей фармакологической активности [10]. Данный факт указывает на то, масло расторопши пятнистой является источником мононенасыщенных и полиненасыщенных жирных кислот при условии сбалансированного поступления $\omega-3$ кислот.

В изучаемом объекте также найдены следы маргариновой $(0,09 \%)$, генэйкозановой $(0,09 \%)$, гептадеценовой $(0,06 \%)$, пентадециловой $(0,03 \%)$, лауриновой кислот $(0,006 \%)$.

Как следует из данных таблицы, состав жирного масла расторопши пятнистой, полученного на базе ЗАО «Самаралектравы», сопоставим с литературными данными по составу масел расторопши пятнистой, 
выращенной в различных географических условиях [7-9], однако впервые были идентифицированы лауриновая кислота $\left(\mathrm{C}_{12: 0}\right)$, пентадециловая кислота $\left(\mathrm{C}_{15: 0}\right)$, гептадеценовая кислота $\left(\mathrm{C}_{17: 1}\right)$, генэйкозановая кислота $\left(\mathrm{C}_{21: 0}\right)$. Данное обстоятельство представляет интерес с точки зрения использования результатов исследования жирнокислотного состава для целей идентификации. Критериями подлинности целесообразно рассматривать: наличие пиков, соответствующих метиловым эфирам линолевой (35-55\% от общего содержания), олеиновой (22-30\%), пальмитиновой (8-15\%), стеариновой $(4,5-12 \%)$, арахиновой $(2-7 \%)$ и бегеновой $(3-8 \%)$.

Кроме того, наличие относительно высокого количества насыщенных жирных кислот в составе жирного масла плодов расторопши пятнистой позволяет объяснить аномально низкое значение йодного числа (60-80) [1].

Жирнокислотный состав масла плодов расторопши пятнистой

\begin{tabular}{|c|c|c|c|c|c|c|c|}
\hline \multirow[t]{2}{*}{ № } & \multirow[t]{2}{*}{ Идентифицированный компонент } & \multirow[t]{2}{*}{$\begin{array}{c}\text { Время } \\
\text { удерживания }\end{array}$} & \multirow{2}{*}{$\begin{array}{l}\text { \% от общего } \\
\text { содержания } \\
\text { суммы жир- } \\
\text { ных кислот } \\
\end{array}$} & \multicolumn{4}{|c|}{$\begin{array}{c}\text { Литературные данные по содержанию } \\
\text { жирных кислот в масле расторопши, \% от } \\
\text { общего содержания суммы жирных кислот }\end{array}$} \\
\hline & & & & [7] & {$[8]$} & [9] & [10] \\
\hline 1 & Лауриновая кислота $\left(\mathrm{C}_{12: 0}\right)$ & 11,05 & $0,01 \pm 0,005$ & - & - & - & \\
\hline 2 & Миристиновая кислота $\left(\mathrm{C}_{14: 0}\right)$ & 12,64 & $0,13 \pm 0,05$ & - & 0,09 & 0,07 & \\
\hline 3 & Пентадециловая кислота $\left(\mathrm{C}_{15: 0}\right)$ & 13,44 & $0,03 \pm 0,005$ & - & - & - & \\
\hline 4 & Пальмитоолеиновая кислота $\left(\mathrm{C}_{16: 1}\right)$ & 14,16 & $0,11 \pm 0,05$ & - & - & 0,05 & \\
\hline 5 & Пальмитиновая кислота $\left(\mathrm{C}_{16: 0}\right)$ & 14,35 & $9,9 \pm 0,2$ & 19,2 & 8,0 & 7,7 & $8-12$ \\
\hline 6 & Гептадеценовая кислота $\left(\mathrm{C}_{17: 1}\right)$ & 15,10 & $0,06 \pm 0,005$ & - & - & - & \\
\hline 7 & Маргариновая кислота $\left(\mathrm{C}_{17: 0}\right)$ & 15,32 & $0,09 \pm 0,01$ & - & - & 0,07 & \\
\hline 8 & Линоленовая кислота $\left(\mathrm{C}_{18: 3}\right)$ & - & - & 0,46 & - & 0,22 & $3-7$ \\
\hline 9 & Линолевая кислота $\left(\mathrm{C}_{18: 2}\right)$ & 16,18 & $34,8 \pm 3,0$ & 43,4 & 56,6 & 48,3 & $35-55$ \\
\hline 10 & Олеиновая кислота $\left(\mathrm{C}_{18: 1}\right)$ & 16,24 & $25,7 \pm 3,5$ & 25,6 & 20,7 & 27,8 & $24-30$ \\
\hline 11 & Стеариновая кислота $\left(\mathrm{C}_{18: 0}\right)$ & 16,44 & $11,4 \pm 1,0$ & 8,7 & 4,8 & 5,0 & \\
\hline 12 & 11-эйкозеновая кислота $\left(\mathrm{C}_{20: 1}\right)$ & 18,52 & $1,6 \pm 0,5$ & - & - & 1,1 & \\
\hline 13 & Арахиновая кислота $\left(\mathrm{C}_{20: 0}\right)$ & 18,84 & $6,9 \pm 0,6$ & 2,63 & 2,7 & 4,0 & \\
\hline 14 & Генэйкозановая кислота $\left(\mathrm{C}_{21: 0}\right)$ & 20,59 & $0,09 \pm 0,005$ & - & - & - & \\
\hline 15 & Бегеновая кислота $\left(\mathrm{C}_{22: 0}\right)$ & 21,45 & $3,8 \pm 0,4$ & - & 2,1 & 3,9 & $3-9$ \\
\hline 16 & Лигноцериновая кислота $\left(\mathrm{C}_{24: 0}\right)$ & 24,11 & $0,54 \pm 0,07$ & - & 0,7 & 1,0 & \\
\hline
\end{tabular}

\section{Abundance}

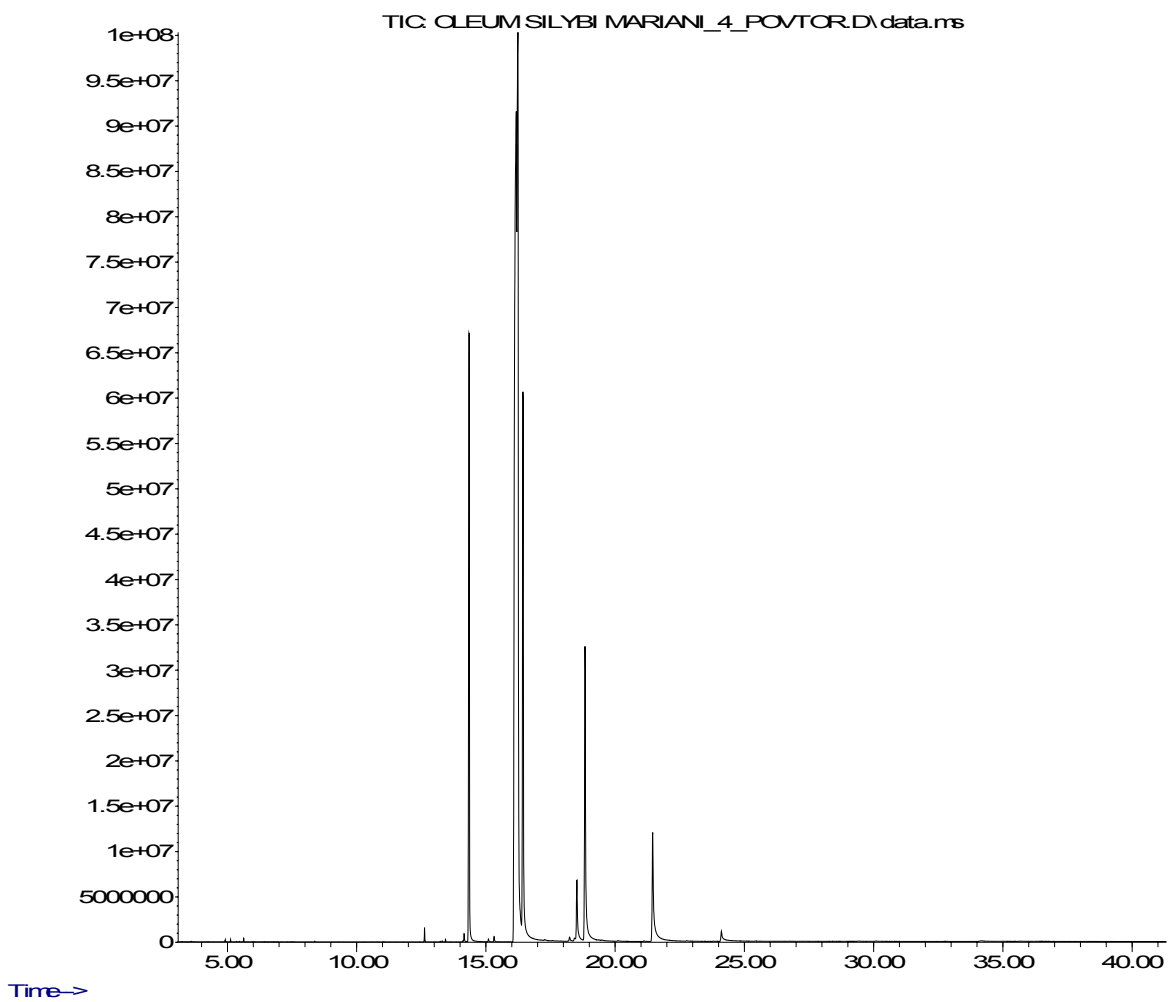

Хроматограмма компонентного состава масла плодов расторопши пятнистой 


\section{Заключение}

Таким образом, подлинность масла расторопши пятнистой можно подтвердить определением состава его жирных кислот, а именно: линолевой (35-55\% от общего содержания), олеиновой (22-30\%), пальмитиновой $(8-15 \%)$, стеариновой $(4,5-12 \%)$, арахиновой $(2-7 \%)$ и бегеновой $(3-8 \%)$ кислот.

\section{Список литературы}

1. Куркин В.А. Фармакогнозия: учебник для студентов фармацевтических вузов (факультетов), 3-е изд. перераб. и доп. Самара, 2016. 1279 c.

2. Куркин В.А., Запесочная Г.Г. Флаволигнаны и другие природные лигноиды. Проблемы структурного анализа // Химия природных соединений. 1987. №1. С. 11-34.

3. Куркин В.А. Расторопша пятнистая - источник лекарственных средств (обзор) // Химико-фармацевтический журнал. 2003. Т. 37, №4. С. 27-41.

4. Луценко С.В., Фельдман Н.Б., Луценко Е.В., Быков В.А. Растительные флаволигнаны. Биологическая активность и терапевтический потенциал. М., 2006, 235 с.

5. Самигуллина Л.И., Лазарева Д.Н. Новые перспективы применения препаратов расторопши пятнистой // Экспериментальная и клиническая фармакология. 2004. Т. 67, №4. С. 77-80.

6. Сокольская Т.А. Комплексная переработка плодов расторопши пятнистой и создание на ее основе препарата «Силимар» // Химико-фармацевтический журнал. 2000. Т. 34, №9. С. $27-30$.

7. Ismaili S.A., Harhar H., Gharby S. et al. Chemical composition of two non-conventional oils in Morocco: Melia azadirachta and Silybum marianum (L.) // Journal of Materials and Environmental Science. 2016. Vol. 7, №6. Pp. 2208-2213.

8. EMA/HMPC/294188/2013 Committee on Herbal Medicinal Products (HMPC), Assessment report on Silybum marianum (L.) Gaertn., fructus, 2015.

9. ГОСТ 31665-2012, Масла растительные и жиры животные. Получение метиловых эфиров жирных кислот.

10. Субботина М.А. Физиологические аспекты использования жиров в питании // Техника и технология пищевых производств. 2009. №4. С. 54-57.

Поступило в редакиию 11 января 2017 г.

После переработки 9 февраля 2017 г. 
Kurkin V.A.", Sazonova O.V., Rosikhin D.V., Ryazanova T.K. THE FATTY ACID COMPOSITION OF OIL FROM SILYBUM MARIANUM, CULTIVATED IN SAMARA REGION

Samara State Medical University, Chapaevskaia st., 89, Samara, 443099 (Russia), e-mail: Kurkinvladimir@yandex.ru

The fruits of milk thistle [(Silybum marianum (L.) Gaertn.), Composite family] are widely used in medical practice as a hepatoprotective agent because they contain flavolignans. However, besides flavolignans, an important group of bioactive compounds of fruit is a fatty oil. The aim of the research was to study the fatty acid composition of milk thistle fruit oil by means of chromatographic-mass spectrometric methods. The object of the study was the oil obtained in the factory "Samaralektravy" from the fruits of milk thistle, cultivated industrially in the Samara region. It was identified 15 fatty acids. The main identified components were unsaturated linoleic $\left(\mathrm{C}_{18: 2} ; 34.8 \pm 3.0 \%\right)$ and oleic acids $\left(\mathrm{C}_{18: 1} ; 25,7 \pm 3,5 \%\right)$, and the saturated stearic $\left(\mathrm{C}_{18: 0}\right.$; $11,4 \pm 1,0 \%$ ), palmitic $\left(\mathrm{C}_{16: 0} ; 9,9 \pm 0,2 \%\right)$, arachidic $\left(\mathrm{C}_{20}: 0 ; 6,9 \pm 0,6 \%\right)$ and behenic acids $\left(\mathrm{C}_{22: 0} ; 3,8 \pm 0,4 \%\right)$. The oil contained $61 \%$ unsaturated fatty acids and $39 \%$ saturated fatty acids. The gas chromatographic method can be useful for identification of a potential pharmaceutical substance "Milk thistle oil".

Keywords: Milk Thistle, Silybum marianum (L.) Gaertn, fruits, milk thistle oil, saturated and unsaturated fatty acids.

\section{References}

1. Kurkin V.A. Farmakognoziia. [Pharmacognosy]. 3 ed. Samara, 2016, 1279 p. (in Russ.).

2. Kurkin V.A., Zapesochnaia G.G. Khimiia prirodnykh soedinenii, 1987, no. 1, pp. 11-34. (in Russ.).

3. Kurkin V.A. Khimiko-farmatsevticheskii zhurnal, 2003, vol. 37, no. 4, pp. 27-41. (in Russ.).

4. Lutsenko S.V., Fel'dman N.B., Lutsenko E.V., Bykov V.A. Rastitel'nye flavolignany. Biologicheskaia aktivnost' i terapevticheskii potentsial. [Plant flavolignanes. Biological activity and therapeutic potential]. Moscow, 2006, 235 p. (in Russ.).

5. Samigullina L.I., Lazareva D.N. Eksperimental'naia i klinicheskaia farmakologiia, 2004, vol. 67, no. 4, pp. 77-80. (in Russ.).

6. Sokol'skaia T.A. Khimiko-farmatsevticheskii zhurnal, 2000, vol. 34, no. 9, pp. 27-30. (in Russ.).

7. Ismaili S.A., Harhar H., Gharby S. et al. Journal of Materials and Environmental Science, 2016, vol. 7, no. 6, pp. 2208-2213.

8. EMA/HMPC/294188/2013 Committee on Herbal Medicinal Products (HMPC), Assessment report on Silybum marianum (L.) Gaertn., fructus, 2015.

9. GOST 31665-2012. Masla rastitel'nye i zhiry zhivotnye. Poluchenie metilovykh efirov zhirnykh kislot. [The state standard is 31665-2012. Vegetable oils and animal fats. Preparation of methyl esters of fatty acids]. Moscow, 2012. (in Russ.).

10. Subbotina M.A. Tekhnika i tekhnologiia pishchevykh proizvodstv, 2009, no. 4, pp. 54-57. (in Russ.).

Received January 11, 2017

Revised February 9, 2017

\footnotetext{
* Corresponding author.
} 
